\title{
UK scientists apply for licence to edit genes in human embryos
}

Team from London's Francis Crick Institute wants permit to use CRISPR/Cas9 technology in basic research.

Daniel Cressey, Alison Abbott \& Heidi Ledford

18 September 2015 I Updated: 18 September 2015

Scientists in London have asked for permission to edit the genomes of human embryos - a request that could lead to the world's first approval of such research by a national regulatory body.

Kathy Niakan, a researcher affiliated with the Francis Crick Institute, London's new $£ 700$ million (US\$1.1-billion) biomedical-research centre, said on 18 September that she is proposing to use gene editing to provide "fundamental insights into early human development". In a statement released through the Crick, Niakan said that her team wanted to use technology based on the CRISPR/Cas9 system - a recently developed technique for precisely editing genomes that has become hugely popular in the biology community. Her application was first reported by The Guardian newspaper.

Editing the genomes of human embryos for a therapeutic use — for example, to eradicate a



Kathy Niakan. genetic disease - is illegal in the United Kingdom, but research work is possible under licence from the Human Fertilisation and Embryology Authority (HFEA). The body, which regulates fertility treatment and embryo research, has confirmed that it has received its first application for a gene-editing licence using CRISPR/Cas9. "It will be considered in due course," the HFEA said.

In April this year, Nature revealed that a Chinese team had, for the first time, reported using the CRISPR/Cas9 technique to edit the genomes of human embryos. The work, led by Junjiu Huang, a gene-function researcher at Sun Yat-sen University in Guangzhou, involved attempts to modify the gene underlying the blood disorder $\beta$ thalassaemia. The research used non-viable embryos that could not result in a live birth, but nonetheless caused huge controversy.

Robin Lovell-Badge, a developmental biologist at the Francis Crick Institute, emphasized to Nature that whereas Huang and colleague's paper explored the correction of a genetic defect that would lead to disease, Niakan's work proposes asking more basic questions about human-embryo development. "Kathy has no intention of making changes to the genome for clinical application," he says.

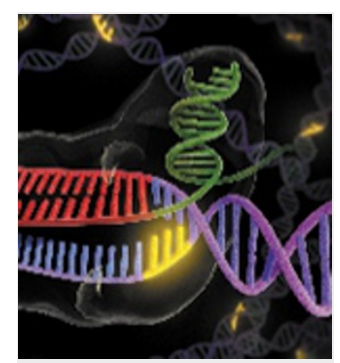

Nature special: CRISPR

Lovell-Badge says that China has guidelines on gene-editing work in embryos, "but these are not quite laws, and there would only have been local ethics committee approval". By contrast, if Niakan's application were given a license, it would mark "the first approval by a national regulator," he says. 


\section{Regulatory debate}

Huang's team's April report spawned a flurry of scientific and policy meetings and statements as governments and policy experts wrestled with how or whether to draw the line on gene editing in human embryos.

Shortly after the work was published, the US National Institutes of Health reaffirmed its ban on funding gene-editing research in human embryos - a ban that would likely also apply to non-viable embryos, it said.

But on 2 September, five UK research organizations - including the Wellcome Trust and the Medical Research Council — issued a statement urging the continued use of CRISPR/Cas9 in research, even in human embryos when ethically justifiable and legal.

A week later, a network of stem-cell researchers, bioethicists and policy experts called the Hinxton Group, said that after meetings in Manchester, UK, they had concluded that research involving genome editing in human embryos has "tremendous value to basic research".

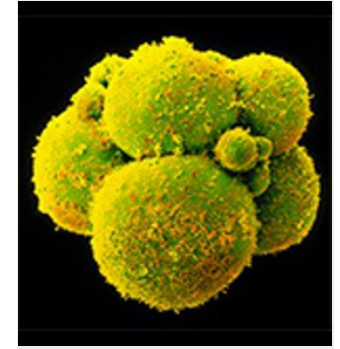

Chinese scientists genetically modify human embryos

And on 14 September, Britain's Royal Society and the Chinese Academy of Sciences announced that they would join forces with the US National Academy of Sciences and the US National Academy of Medicine to host a summit in December on germline editing (genetic changes to embryos, sperm and eggs).

\section{Closely watched}

The HFEA application is likely to be closely watched by researchers around the world, because the regulator has a global reputation for careful but progressive regulation of human-embryo work.

Sarah Chan, a bioethics researcher at the University of Edinburgh, UK, says there is confusion around what is permitted in different parts of the world regarding human-genome editing. Good regulation, she says, can help to make clear to scientists what they can and cannot do. "Because of its history of successful regulation, the UK could serve as a model for other countries," she says.

"While I am certain that people in other countries will be paying close attention to both how the HFEA handle this licence application and, if it is granted, how the research progresses, it does not really warrant this attention," says Lovell-Badge. "The use of genome-editing techniques in this context is really the same as using any other method on an embryo that is not going to be implanted into a woman, and which will be destroyed after a few days of culture".

Nature | doi:10.1038/nature.2015.18394

Tweet Follow @NatureNews

\section{- Updates}

Updated:17:16 BST: This article has been updated to clarify the statement made by the Hinxton Group.

\section{SPRINGER NATURE}

